\title{
Investigation of Performance Characteristics of Hybrid Cars
}

\author{
B. R. Qawasmeh*, A. Al-Salaymeh, A. Swaity, A. Mosleh, S. Boshmaf \\ Mechanical Engineering Department, The University of Jordan, Amman 11942, Jordan
}

\begin{abstract}
The study aims to establish a comparison between different cars models (conventional and hybrid) from various manufacturers sold in the local Jordanian market. The aspects covered are the main performance parameters such as the output horsepower, hybrid system type used and the economic parameters including net present prices, miles travelled per gallon (MPG) and the payback period. In addition, we study the environmental aspect such as $\mathrm{CO}_{2}$ gas emissions. Moreover, some special aspects related to hybrid cars are studied to give better view of the new hybrid technology found in the world nowadays .Here, we collect data from previous studies and from the manufacturers' data sheets as well as from local and international car experts and dealers. Then the data is arranged to deliver a clear view about the hybrid technologies. The study serves as a car selection guide, which contains the main parameters needed for all users and a technical review for researchers interested in the automotive industry of conventional/hybrid cars. As a result, the new hybrid car technology can be categorized into three main types (series, parallel, or series/parallel system), and into four main levels (Micro, Mild, Full, and Plug in). Toyota's HSD (hybrid Synergy Drive also used by Nissan and Lexus) is a series/parallel hybrid system, while Honda's IMA (Integrated Motor Assist) system and Hyundai hybrid system are from parallel hybrid type. Economically, over the full models range, Toyota Prius has the largest MPG of 51, which is constant throughout models range, thus having the highest annual saving of $421 \mathrm{JOD} /$ year. However, Honda Insight and Honda Civic hybrid have lower payback periods due to their lower initial prices. Environmentally, Toyota Prius has the least $\mathrm{CO}_{2}$ emissions of $178 \mathrm{~g} / \mathrm{mile}$; also, $\mathrm{HEVs}$ have lower $\mathrm{CO}_{2}$ emissions than their conventional counterparts over all the models. Comparing HEVs' output power to their conventional counterparts with the same engine size, HEVs have same or better output power. In summary, HEVs are recommended to replace the conventional cars, due to their ability of reducing $\mathrm{CO}_{2}$ emissions, fuel consumptions, and offering slightly better performance.
\end{abstract}

Keywords: Hybrid Cars, Conventional Cars, $\mathrm{CO}_{2}$ emission

\section{Introduction}

Hybrid cars have recently seen increased usage around the world, hybrid electric vehicles (HEVs) named hybrid since they have two separate installations for power, which are the conventional fuel driven Internal Combustion Engine (ICE), and the electric motor driven by a separate electrical system. A noticeable thing that one must not be confused about, is that HEVs are not electric vehicles, electric vehicle's power system consists only of a battery powered electrical system without any fuel fed components, whereas HEV has both power developers systems simultaneously (i.e. the conventional fuel fed ICE and the electrical system). Figure 1 shows the difference between HEVs and EV.

All HEVs have two power sources (i.e. ICE and the electric motor) they are categorized upon their input to output configuration (hybrid cars type), and upon the size of the existing electrical system and its amount of participation in the developed torque (hybrid Levels) [4].

The history of hybrid cars has been around since the industry of automobiles. Austrian engineer Ferdinand Porsche built the first HEV, in 1898. The system was called Lohner-Porsche Mixte, it used an ICE to drive a generator and provide the power to the electric motor located at the front of the car to power the front wheels. The Mixte was well received, and over 300 were produced.

${ }^{*}$ Corresponding author. Tel.: +962-6-5355000 ext. 22807

Fax:+962-6-530 0813; E-mail: b.qawasmeh@ju.edu.jo

(C) 2017 International Association for Sharing Knowledge and Sustainability

DOI: $10.5383 /$ ijtee.14.01.008 


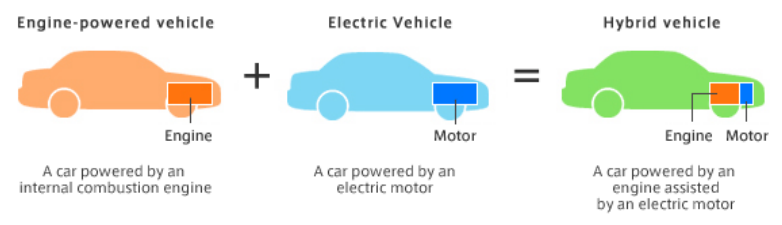

Figure 1: The basis of the HEV [1]

Then, the industry of the HEV observed severe decline due to the ability of many car manufacturer companies to produce cheap and powerful fuel-powered vehicles. As the awareness of the global warming phenomenon increased in the $60 \mathrm{~s}$, governments around the world started to encourage the use of electric vehicles by introducing some legislation as in the U.S in order to reduce air pollution, but this encouragement had not gained a great importance until the Arab oil embargo in 1973. This oil crisis caused the price of gasoline to soar while supply fell dramatically. This oil crisis led the car manufacturers' to spend billions on research aiming to develop hybrid and Electrical cars' systems. In 1999 Honda introduced the first mass-production HEV, the Honda Insight, was a two-door and two-seat car. However, the Toyota Prius sedan, which was released in 2000 in the U.S market, was the HEV that gave the hybrid technology its importance. Where other car manufactures used its technology as a base for many other vehicles [2].

Currently, the automobile market is expanding, increasing the number of automobiles on roads, energy consumption is increasing every year that led to the fear that at current rate fossil fuels will run out in the near future, and the reduction of $\mathrm{CO}_{2}$ emissions to prevent aggravation of the global warming phenomenon has become an international issue. These three reasons sum up why having an Eco-car (which has good fuel economy and low $\mathrm{CO}_{2}$ emissions) is necessary. The new HEV technology resembles the core technology for developing the ultimate Eco-car [3]. HEVs have many preferable potentials that make them suitable for both features (good fuel economy and low $\mathrm{CO}_{2}$ emissions), the addition of the electric motor improves the fuel efficiency of the vehicles. Besides that, the electric motor is capable of delivering its maximum torque starting from rest, this will incredibly enhance the driving performance too. Furthermore, better fuel efficiency means lower $\mathrm{CO}_{2}$ emissions leading to even more environmentally friendly automobiles [1].

The study includes investigation of several types of hybrid cars sold in the local market in Jordan. This includes both performance characteristics and economic feasibility. Data were collected from previous studies, and manufacturers' data sheets. Detailed economic feasibility study has been carried out along with a performance characteristics study. The aim was to determine the main economic parameters important to the users. This includes net present values, and payback periods for some car models in comparison with conventional cars, and by doing a sensitivity analysis to show the effect of fuel prices and mileage per year. Results of the study were formulated in various formats and levels to serve as general guidelines for different sectors including direct beneficiaries' public bodies and academic institutes.

\section{BACKGROUND}

\subsection{HEVs Systems Types}

Hybrid cars are categorized upon the configuration of both electrical and conventional systems, and the way both systems interact to produce the required propulsion torque.

The electrical system which is added to the conventional ICE system, consists primarily of three main components: electrical battery acts like a storage for the electrical energy, electrical inverter/converter unit(s) used to manage the recharging and power circuits in hybrid cars (inverter is used to convert the high DC voltage from the battery to 3-phase AC for the motor, while the converter is used to step the DC voltage up or down), and the motor/generator unit(s) which can be presented as a separate motor and generator, or as a single unit acts as a motor or as a generator depending on the input to output power configuration [1].

Hybrid systems fall under three main types:

Series Hybrid; the electrical motor always drives the wheels, and the function of the ICE is only to drive a generator to power the electric motor and to charge the electric battery

Parallel Hybrid; both the ICE and the electric motor are capable of driving the wheels simultaneously. Moreover, driving the wheel by the motor only is also possible.

Series/parallel Hybrid (power split type); a Parallel system with the addition of a small Series element [6], the power produced by the ICE is distributed into two divisions, the first one is to drive the generator either to charge the battery or to power the motor, the second is to directly drive the wheels.

\subsection{HEVs Levels}

HEVs are also classified upon their electrical system size and their amount of participation in assisting the work of the ICE. There are four main Hybrid levels found in cars' market:

Micro; equipped with a small integrated motor (or starter) to allow the vehicle to stop the ICE completely when the driver pushes the brake, then this motor restarts the ICE when the driver releases the brake pedal. This action is called start/stop technology and it is found in all of the HEVs on the roads.

Mild; comes with larger electrical system which allows the motor to assist the work of the ICE at starting and low speeds. However, in mild hybrids the motor alone cannot drive the wheels.

Full; has the same electric system components like that of mild, but have larger size, this electrical system is capable of driving the wheels solely at starting and low speed cruising, also start/stop and also has the regenerative braking technology. In addition, full hybrid has a better control system to optimize the efficiency, the fuel economy and the environmental performance increased significantly (around $40 \%$ ) compared to the conventional cars.

Plug-in hybrid; combines the features of both full hybrids and the full EVs.

\subsection{Batteries Types}

Lead-Acid batteries are the oldest battery types used in the automotive application. It is commonly used as the auxiliary battery (starting battery). The Lead-Acid batteries have lead and lead-oxide electrodes while the electrolyte is strong acid (i.e. sulfuric acid [9]) [16].

The advantages of this type are low cost, good specific power, and life cycle. Disadvantages of this type are the lower specific energy (SE) (energy density), because of the presence of lead, which has high molecular weight and bad temperature characteristics. Also, it does not perform well at low 
temperature, and has potential safety hazards associated with the presence of the highly corrosive sulfuric acid and the released Hydrogen gas as result of the self-discharge reactions which makes it highly flammable gas even in low concentrations [9].

While first HEVs used Lead-Acid batteries, Nickle-MetalHydride (NiMH) batteries have quickly replaced the use of Lead-Acid batteries, because $(\mathrm{NiMH})$ batteries are more environmental friendly and lighter, which mean that they have a better specific power than Lead-Acid batteries.

Honda, Hyundai and Toyota have used NiMH batteries in all of their HEVs (Toyota replaced the NiMH batteries with Li-ion batteries in the Toyota Prius 2016), these batteries are proved to be more durable, and car manufacturers give a warranty of around eight years on their electrical system in HEVs.

Today, Lithium-Ion battery technology has gained a much focus from $\mathrm{HEV}$ manufacturers; this technology has even better specific power than the NiMH batteries. However, LiIon batteries are more expensive than NiMH batteries and have some safety issues when operating at high temperature, thus they need expensive protection circuits [17].

Another battery type is the Lithium Polymer battery; its characteristics are almost the same as Li-Ion Battery, but its more shape flexible and can be packed in a smaller area. Hyundai hybrid System (found in Sonata hybrid) is the first system to use the lithium polymer battery instead of the Lithium Ion or the Ni-MH. Moreover, this battery has a smaller size comparing to the Ni-MH one, thus offering more interior space at the rear trunk [22]. HEVs have three main features shown in Figure 2, which let them have their fuel economy excellence over conventional models.

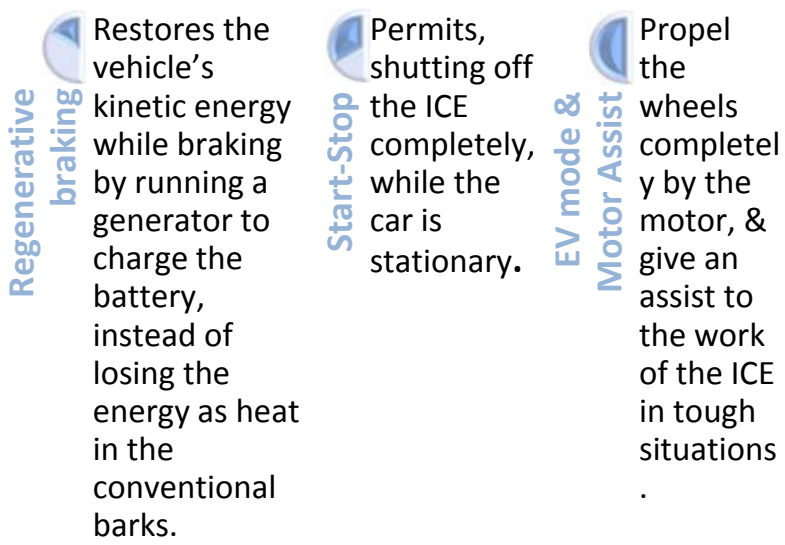

Figure 2: HEVs features

\section{Methodology}

The Jordanian cars' market has plenty of car options, the HEV models are found side by side with the conventional car models. This study intends to investigate the main differences between these two types of cars models, covering performance characteristics (output power), economical characteristics (fuel economy), net-present values, batteries replacement costs, payback periods and annual savings), and environmental performance ( $\mathrm{CO}_{2}$ emissions). The study included models from 2011 to 2015 (and Hyundai Sonata hybrid 2016), Table 1 lists these existing models.
Table 1: List of the included car models in the study

\begin{tabular}{|c|c|c|c|c|c|c|}
\hline Manuf. & Model & $\begin{array}{l}20 \\
11\end{array}$ & $\begin{array}{l}201 \\
2\end{array}$ & $\begin{array}{l}201 \\
3\end{array}$ & $\begin{array}{l}201 \\
4\end{array}$ & $\begin{array}{l}201 \\
5\end{array}$ \\
\hline Toyota & Prius & $\sqrt{ }$ & $\sqrt{ }$ & $\sqrt{ }$ & $\sqrt{ }$ & $\sqrt{ }$ \\
\hline Honda & Insight & $\sqrt{ }$ & $\sqrt{ }$ & $\sqrt{ }$ & $\sqrt{ }$ & - \\
\hline Ford & Fusion & $\sqrt{ }$ & $\sqrt{ }$ & $\sqrt{ }$ & $\sqrt{ }$ & - \\
\hline Honda & Civic $\mathrm{H}$ & $\sqrt{ }$ & $\sqrt{ }$ & $\sqrt{ }$ & $\sqrt{ }$ & - \\
\hline Honda & Civic C & $\sqrt{ }$ & $\sqrt{ }$ & $\sqrt{ }$ & $\sqrt{ }$ & - \\
\hline Hyundai & Sonata H & $\sqrt{ }$ & $\sqrt{ }$ & $\sqrt{ }$ & $\sqrt{ }$ & $\sqrt{ }$ \\
\hline Hyundai & Sonata $\mathrm{C}$ & $\sqrt{ }$ & $\sqrt{ }$ & $\sqrt{ }$ & $\sqrt{ }$ & - \\
\hline Toyota & Camry H & $\sqrt{ }$ & $\sqrt{ }$ & $\sqrt{ }$ & $\sqrt{ }$ & $\sqrt{ }$ \\
\hline Toyota & Camry C & $\sqrt{ }$ & $\sqrt{ }$ & $\sqrt{ }$ & $\sqrt{ }$ & - \\
\hline Nissan & Altima H & $\sqrt{ }$ & - & - & - & - \\
\hline Nissan & Altima C & $\sqrt{ }$ & - & - & - & - \\
\hline Kia & Optima H & $\sqrt{ }$ & $\sqrt{ }$ & $\sqrt{ }$ & $\sqrt{ }$ & $\sqrt{ }$ \\
\hline Kia & Optima C & $\sqrt{ }$ & $\sqrt{ }$ & $\sqrt{ }$ & $\sqrt{ }$ & - \\
\hline Ford & Escape H & $\sqrt{ }$ & - & - & - & - \\
\hline Toyota & $\begin{array}{l}\text { Highlande } \\
\mathrm{rH}\end{array}$ & $\sqrt{ }$ & $\sqrt{ }$ & - & - & - \\
\hline Toyota & $\begin{array}{l}\text { Highlande } \\
\text { r C }\end{array}$ & $\sqrt{ }$ & $\sqrt{ }$ & - & - & - \\
\hline Lexus & LS 600h & - & - & - & - & $\sqrt{ }$ \\
\hline Lexus & NX 300 & - & - & - & - & $\sqrt{ }$ \\
\hline Lexus & IS 300 & - & - & - & - & $\sqrt{ }$ \\
\hline Toyota & Corolla & - & - & - & - & $\sqrt{ }$ \\
\hline
\end{tabular}

\subsection{CAR MANUFACTURERS' HYBRID SYSTEMS}

The actual hybrid systems developed by some main cars' manufacturers and used in their HEVs are given below:

\subsubsection{Hybrid Synergy Drive System (HSD)}

Hybrid Synergy Drive (HSD) system is one of the full hybrid system found in the hybrid cars market, it was invented and developed by Toyota co. and was introduced first in the Toyota Prius hybrid car in 1997 with the name of Toyota Hybrid System (THS). Then second generation Prius (THS II) [18], third generation Prius (THS III), finally the name of the system was changed to HSD in order to be used by other cars brands (Lexus, and Nissan).

This system allows the car to switch between both the ICE and the electric motor in a manner that ensure the most efficient and most environmentally clean way. In addition, it delivers an e-CVT (electronic continuously variable transmission) gear transmission that means the HSD system is capable of delivering the best gear ratio required for both fuel economy and performance depending on the driving situation whether the car needs to charge the battery or to increase its acceleration. Most of the manual and automatic gear transmission cars allow the driver (or automatically) to switch between 4 to 6 gear ratios only, in that way the car would be driving on a non-optimal gear ratio (i.e. the car is less efficient) [19].

The HSD also offers the regenerative breaking technique that plays a key role in improving the fuel economy of the car, the principle here is to use the kinetic energy of the moving car to charge the electrical system battery while breaking, instead of this energy to be dissipated as heat due to friction in the conventional breaking systems. In addition, HSD allows the engine to switch off completely when the car is at rest (startstop technique) this also improves the fuel economy [18]. 


\subsubsection{HSD System Components [18]}

HSD system is composed of the following seven components: Internal Combustion Engine (ICE), Motor/Generator 1, Motor/Generator 2, Planetary Gear Set, Inverter, HV Battery and HV ECU.

\subsubsection{Integrated Motor Assist System (IMA)}

IMA (integrated motor assist) is a parallel hybrid system and was introduced first by Honda in 1999. By choosing the parallel configuration in which the main power comes from the ICE; Honda managed to achieve simpler, lighter, and more affordable hybrid system which can enhance the performance and efficiency of the car. Honda Insight 1999 was packed with the first IMA system generation, second generation was found in the Civic hybrid 2002, and the third was the accord hybrid 2004. All these three IMA generation were known to be 'mild' hybrid systems in which the electrical motor alone cannot drive the car, instead its primary duty was only to assist the work of the ICE [8].

In the fourth IMA generation that was introduced in 2006 in Civic model was the first Honda hybrid system, which can be seen as a 'strong' hybrid system; since it has introduced the EV (electric vehicle) mode. This driving mode allowed the electrical motor alone to drive the car when it is cruising at a low speed. As in the other hybrid systems found in the market, the IMA also has the regenerative braking technology; this technique combined with the new 3-stage iVTEC engine (found in the Honda Civic models) has achieved an astonishing energy restoring capacity. The iVTEC offers an improved valve timing in which the engine valves would be deactivated while deceleration resulting in reducing the pumping loss in the engine cylinders. Also the IMA offers the 'start-stop' mode in which the ICE is completely shut off when the car is stopped [1].

The main IMA components are the Motor/Generator unit, the ICE, the CVT; these three components are attached to each other in the front of the car, other components including the IPU (Intelligent Power Unit) and the Ni-MH battery are packed at the rear of the car [8].

\subsubsection{Hyundai Hybrid System}

Hyundai hybrid system was introduced in its Sonata model, this hybrid system was designed to give an astonishing highway driving mileage up to $40 \mathrm{mpg}$, the system is considered to be a parallel full hybrid system and it is similar to Honda IMA system but with some slight differences.

The main components of this system are; an Atkinson cycle ICE, HSG (Hybrid Starter Generator), Electrical motor, lithium polymer battery, and an automatic transmission. Other components include the inverter and power controlling units.

This hybrid system is the first full hybrid system to use a sixspeed automatic transmission rather than the CVT (which can be found in most of other hybrid cars). In addition, the motor and the engine here are not attached to each other directly (as in the IMA system) instead there is a clutch disk found between them. This clutch is used to detach the engine shaft from that of the motor when the motor alone drives the wheels (IMA system deactivates the engine valves in such situation instead of this separation "detachment") [21].
This hybrid system as other hybrid systems found in the world offers the regenerative braking and start-stop techniques in order to increase the fuel efficiency by reducing the lost power.

\subsection{THE ANALYSIS AND COMPARISON}

\subsubsection{Performance Characteristics}

In this part, three performance characteristics (engine size, output horsepower, and torque) are listed in a table and plotted in a graph for each year of manufacturing. Noting that all the performance characteristics listed are referenced to Edmunds Inc. [23].

2011: The performance of the FWD cars are as follows; the highest output HP is for Altima conventional model which is $270 \mathrm{HP}$, since it comes with relatively big engine $(3.5 \mathrm{~L})$, however there is another Altima version which comes with a $2.5 \mathrm{~L}$ engine, but it is not common in the local market.

AWD vehicles are ford escape hybrid and Toyota highlander (conventional and hybrid), the difference in performance is clear, thus the Highlander has much more power to deliver ( $270 \& 280 \mathrm{HP}$ respectively were its only $177 \mathrm{HP}$ for the Ford Escape). Kia Optima and Hyundai Sonata hybrid have the same output power of 206 HP. Honda hybrid cars (Civic and Insight) have the smallest engines size among the rest of the hybrid cars $(1.3 \mathrm{~L})$. Comparing each conventional car with its hybrid counterpart, HEVs' output power is slightly higher, when the engine size is the same (all mentioned except the Honda Civic). The best output HP among the FWD hybrid cars is the Sonata hybrid and optima hybrid that can deliver 206 HP. Figure 3 represents 2011 models performance characteristics.

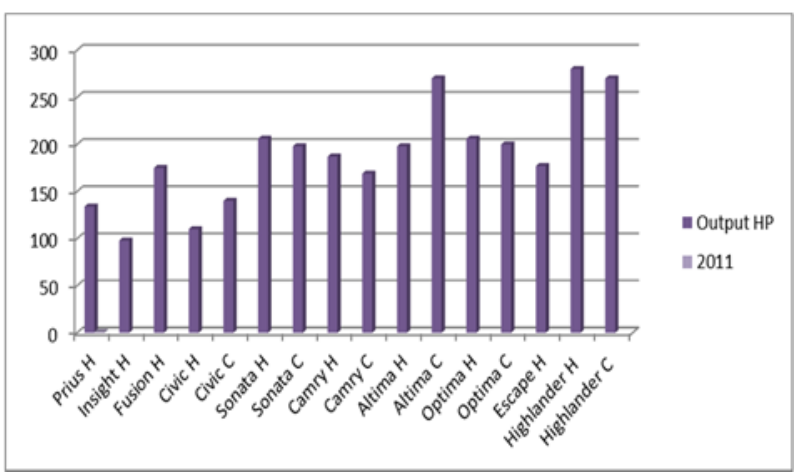

Figure 3: 2011 cars models performance characteristics

2012: Nothing much has changed except the Honda Civic hybrid has a larger engine $(1.5 \mathrm{~L})$ instead of $(1.3 \mathrm{~L})$ in the previous model. In addition, Toyota Camry increased its output power (200 and $178 \mathrm{HP}$ for hybrid and conventional respectively instead of 187 and $169 \mathrm{HP}$ ). Figure 4 represents 2012 models performance characteristics.

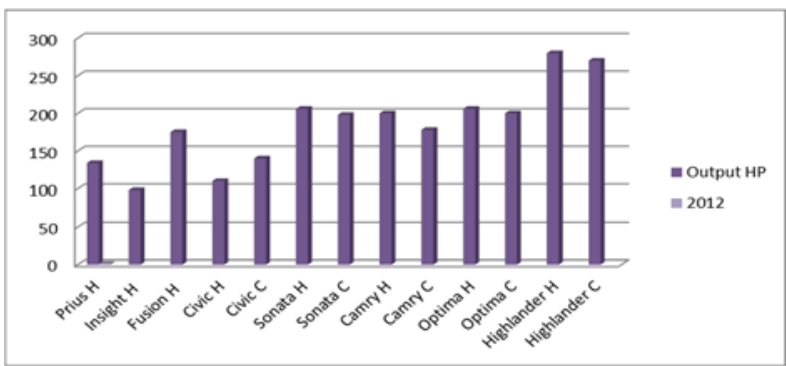

Figure 4: 2012 cars models performance characteristics 
2013: Only Ford Fusion has reduced its engine size from $2.5 \mathrm{~L}$ to $2.0 \mathrm{~L}$. However, its performance gets better (from $175 \mathrm{HP}$ to $188 \mathrm{HP}$ in the latter model). Camry hybrid, optima hybrid, and Sonata hybrid had almost the same output power of $200 \mathrm{HP}$. Figure 5 represents 2013 models performance characteristics.

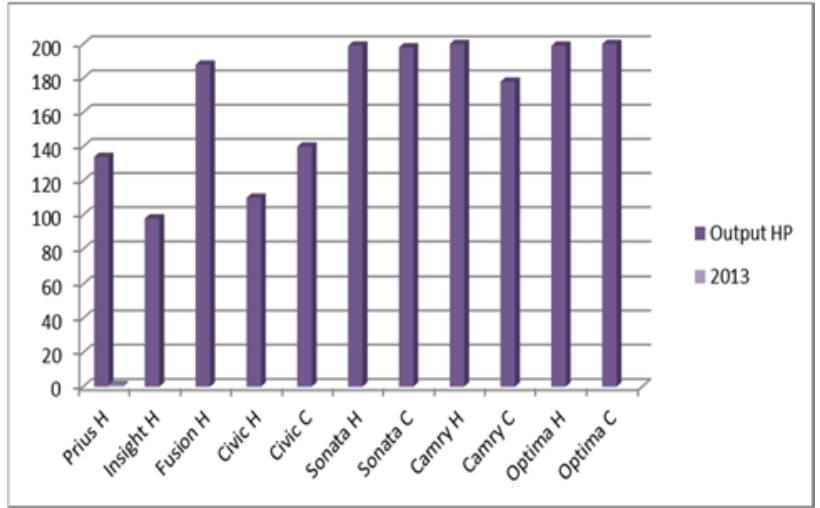

Figure 5: 2013 cars models performance characteristics

2014: Performance characteristics for 2014 models are the same as in the previous 2013 models. Figure 6 represents 2014 models performance characteristics.

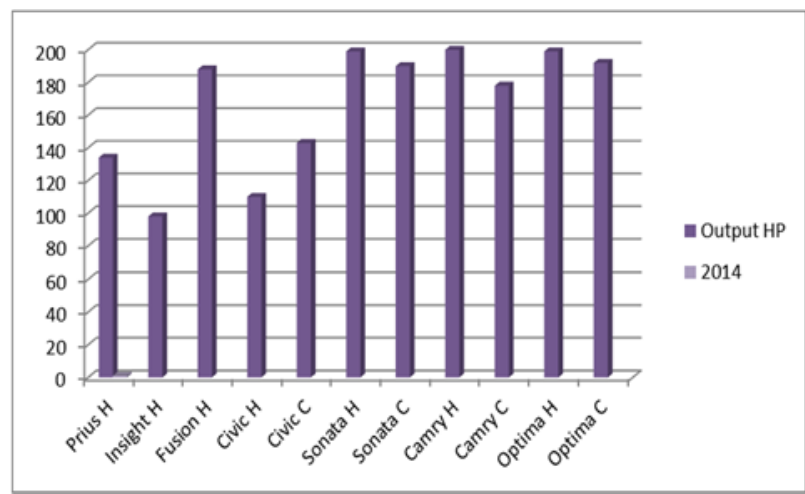

Figure 6: 2014 cars models performance characteristics

2015 \& 2016: In this year, we put only the brand new hybrid cars, which the manufacturers' authorized dealers sell in the local market. Unfortunately, not every model is available, since that Ford, Honda, and Nissan do not sell any brand new hybrid cars, also Toyota does not sell the conventional Camry, and Kia also does not sell the conventional Optima.

Lexus cars have a variety of hybrid cars options; sport AWD (i.e. IS 300h), SUVs (i.e. NX 300h), and Luxury car (i.e. LS 600). There are many available hybrid Lexus models in the local market like the ES, GS, etc.

Sonata hybrid 2015 (Yf) with Theta II 2.4 L ICE, which utilizes the Atkinson cycle and so increasing the engine efficiency. New Sonata hybrid 2016 (Lf) comes with the Nu 2.0L GDI and it does not come with Theta II engine. [22]

Note that the Toyota Prius performance never changed over the 2011-2015 models. Figure 7 represents 2015 models performance characteristics.

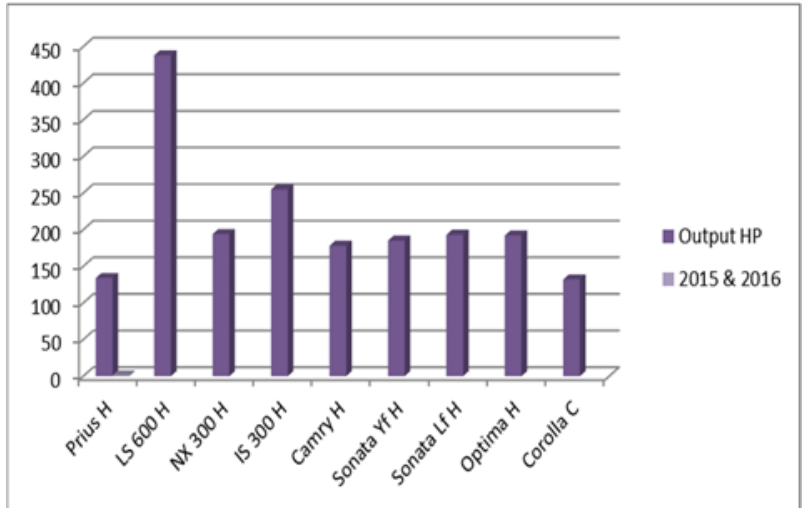

Figure 7: 2015 and 2016 cars models performance characteristics

\subsubsection{Environmental Performance ( $\mathrm{CO}_{2}$ Emissions)}

Here the $\mathrm{CO}_{2}$ emissions of each car is listed and shown in graphs, noting that all the values of the $\mathrm{CO}_{2}$ emissions are referenced to the Environmental Protection Agency, EPA, in U.S [24]. Figures 8-12 show the $\mathrm{CO}_{2}$ emissions for models from 2011 until 2015 respectively.

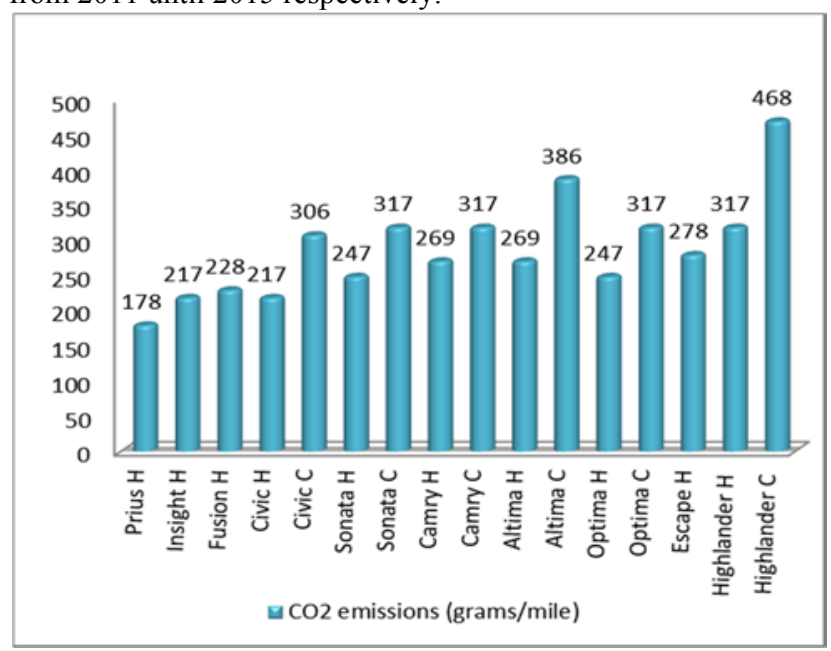

Figure 8: $\mathrm{CO}_{2}$ emissions for 2011 models

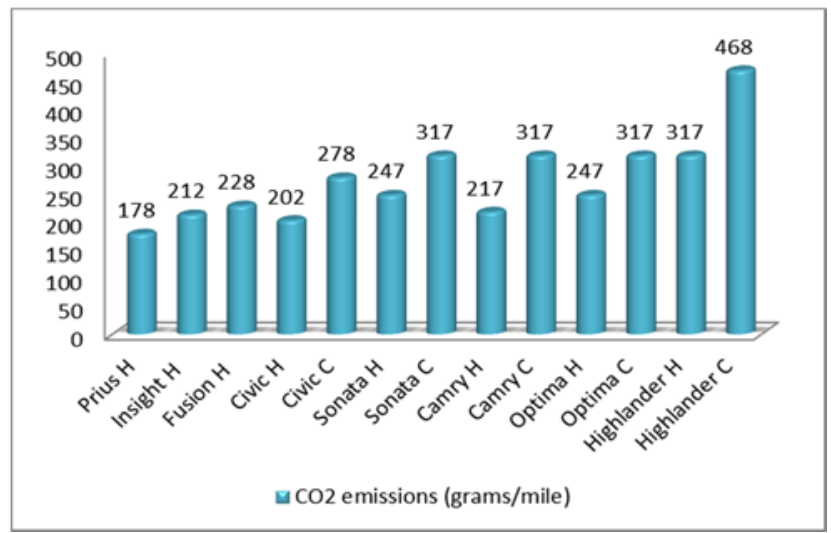

\section{Figure 9: $\mathrm{CO}_{2}$ emissions for 2012 models}

The best $\mathrm{CO}_{2}$ emissions (lowest) was for the Toyota Prius (178 $\mathrm{g} / \mathrm{mile}$ ), the worst was for the conventional Toyota Highlander (468 g/mile). Environmentally, $\mathrm{HEVs}$ have lower $\mathrm{CO}_{2}$ emissions than their conventional counterparts do.

Among conventional the best is the Honda Civic (306 g/mile), which is not much lower than, Sonata, Camry, Optima that all have the same emissions value of $317 \mathrm{~g} / \mathrm{mile}$. 


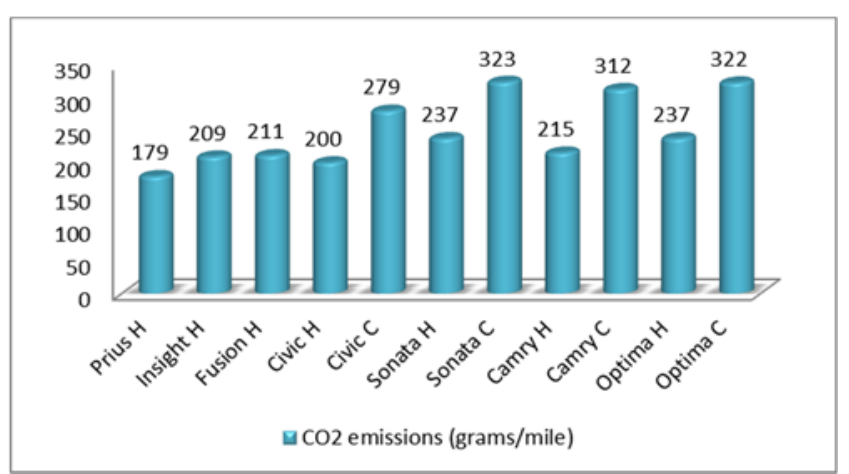

Figure 10: $\mathrm{CO}_{2}$ emissions for 2013 models

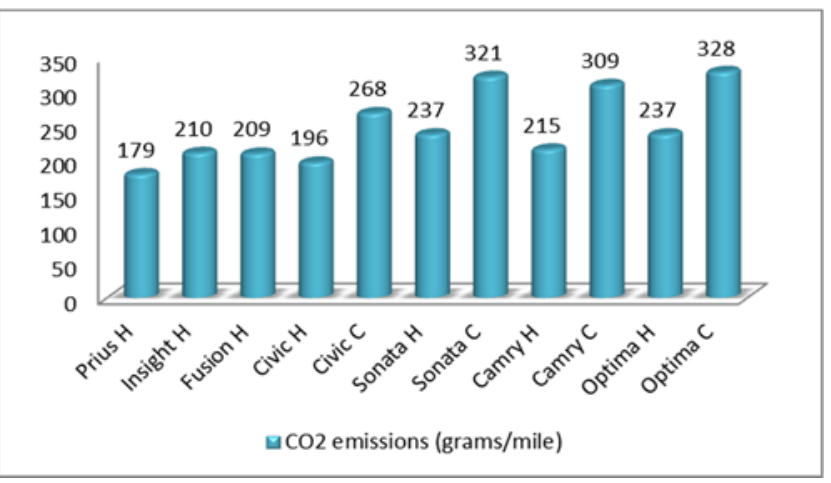

Figure 11: $\mathrm{CO}_{2}$ emissions for 2014 models

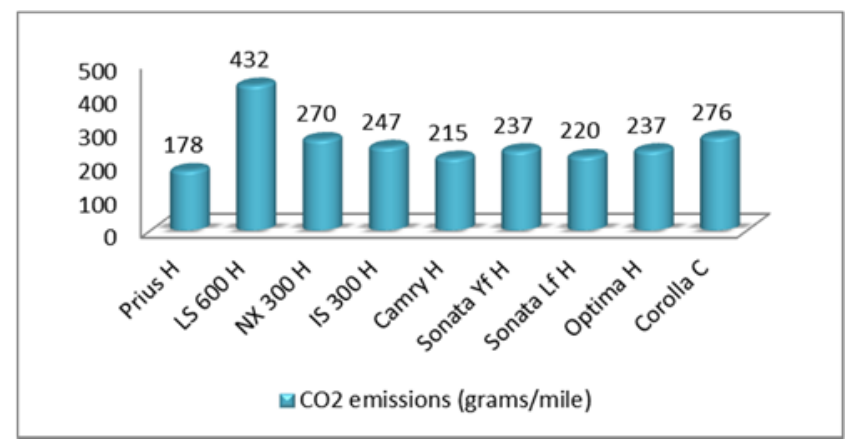

Figure 12: $\mathrm{CO}_{2}$ emissions for 2015 models

The Toyota Prius maintained its position in the lead, with the lower $\mathrm{CO}_{2}$ emissions (around $178 \mathrm{~g} / \mathrm{mile}$ ), over the five years. The conventional Toyota Highlander (2011 and 2012) has highest emission $468 \mathrm{~g} / \mathrm{mile}$.

\subsubsection{Economical Characteristics}

This section is about investigating the economical characteristics of HEVs, the main objects studied are the netpresent value in the local market, the annual saving, payback periods considering the average MPG of 2016 models, and the extra maintenance costs of the HEVs over the conventional cars (Batteries replacement costs).

\section{- Miles Per Gallon (MPG)}

The data for MPGs are all referenced to the EPA as in the $\mathrm{CO}_{2}$ emissions section, however the values published by the car' manufacturers' may differ than that taken from the EPA.
The values of MPG are divided into three types; City driving (low speeds and somewhat traffic), Highway driving (high speed cruising), and combined driving (it is the average based on $45 \%$ highway, $55 \%$ city driving). The most common counterpart of the MPG in the local market is $(\mathrm{km} / 20 \mathrm{~L})$.

For each model data for MPG (also the $\mathrm{km} / 20 \mathrm{~L}$ ) is put in table and plotted in a separate figure. Figures 13-17 show MPG data for 2011 till 2015 models respectively.

2011: Ford Escape has better MPG than the Toyota Highlander hybrid (32 MPG instead of 28 MPG for the latter).

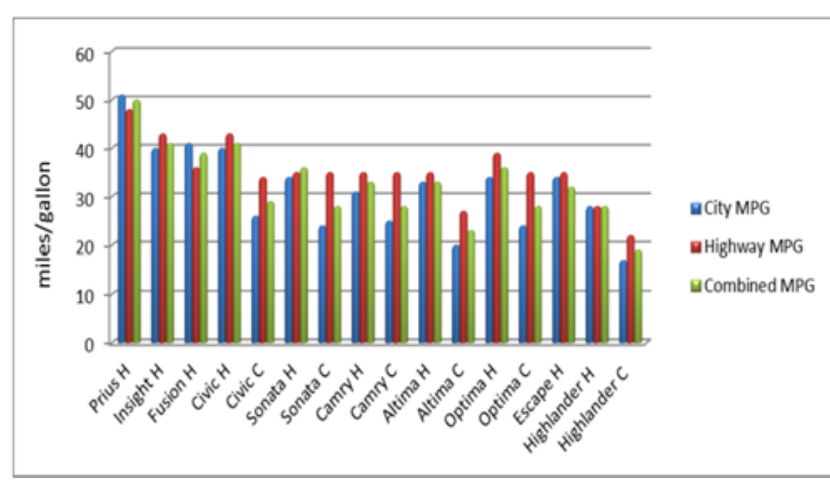

Figure 13: MPG values for 2011 models

2012: Toyota Camry hybrid shows an increase in the combined MPG (41 instead of 33 for the previous 2011 model). Honda Civic has also improved (32 and 44 for conventional and hybrid models respectively, instead of 29 and 41 for 2011 models).

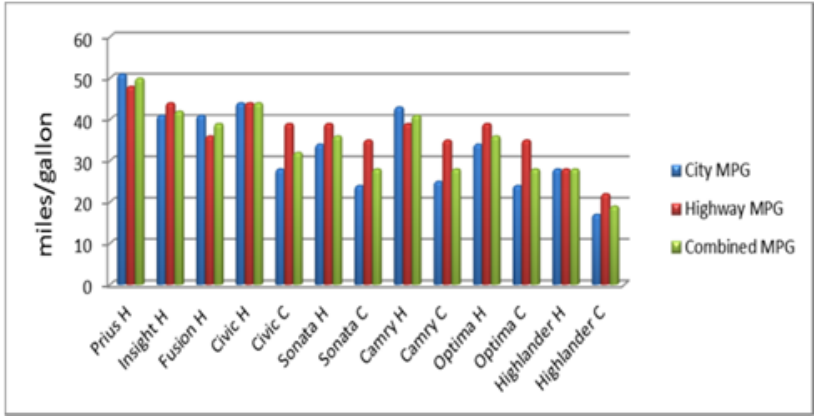

Figure 14: MPG values for 2012 models

2013: At this year, Ford Fusion has an improved MPG due to a new Engine size (42 MPG instead of 39 MPG for previous 2012 and 2011 models). Optima and Sonata hybrid have the same MPG (36 for 2011 models and 38 for 2012 models).

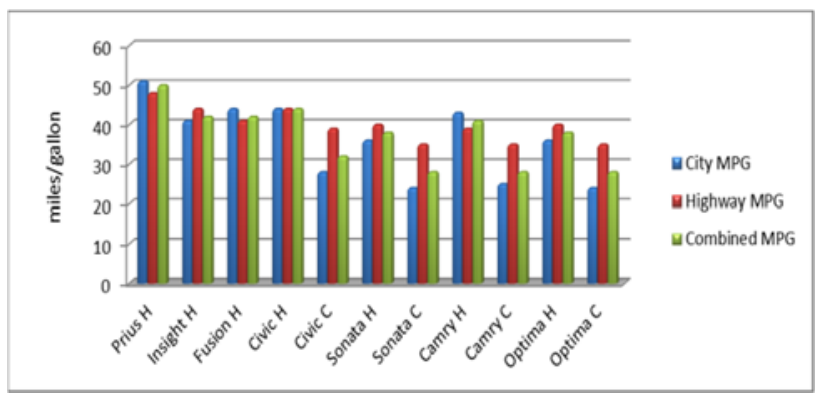

Figure 15: MPG values for 2013 models 
2014: Models in 2014, have maintained their MPGs.

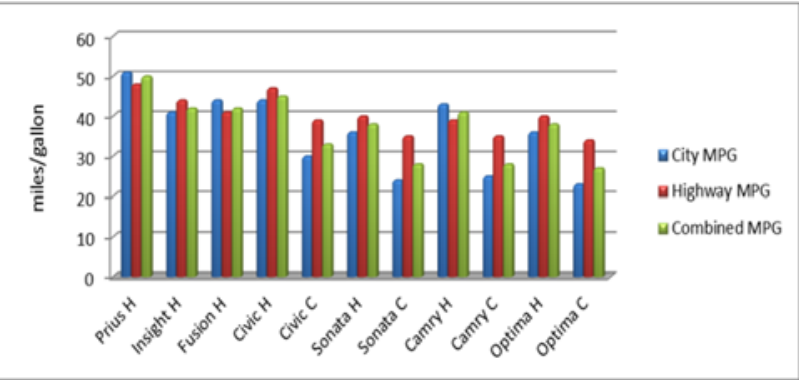

Figure 16: MPG values for 2014 models

2015 \& 2016: Sonata hybrid 2016 (Lf) has increased its MPG to 41 instead of 38 , thus reaching the same MPG of the Toyota Camry hybrid.

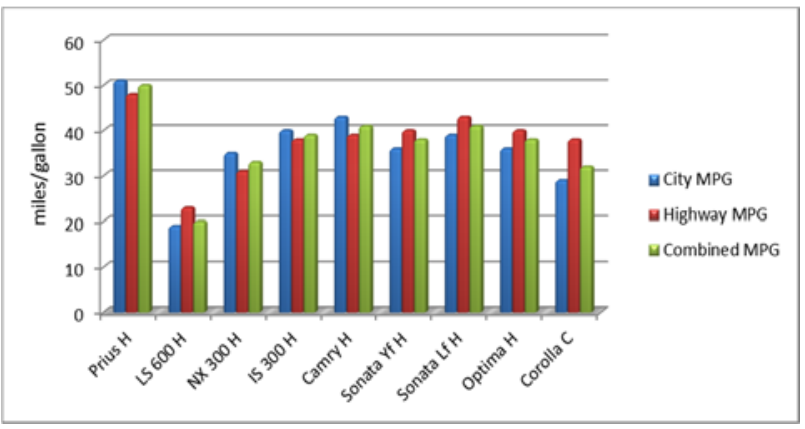

Figure 17: MPG values for 2015 and 2016 models

The Toyota Prius is in the lead when concerning the MPG values, with MPG around 51. The Honda Civic hybrid 2013 has the nearest MPG value of 45 .

\section{- Net-Present Value, Annual Saving, and Payback Period}

For each model data for economical characteristics (net-present values, payback periods, and annual savings) are put in table and plotted in a separate figure. Figures from 3.2.16 to 3.2.20 show these data for 2011 to 2015 models respectively.

2011: The value of annual saving for Highlander $C$ and Altima $\mathrm{C}$ were negative due to their combined mileage being below the average combined mileage assumed (25 MPG), and thus they have no payback period. Higher annual saving is considered better, however both present value and annual saving determine the payback period. (Figure 18)

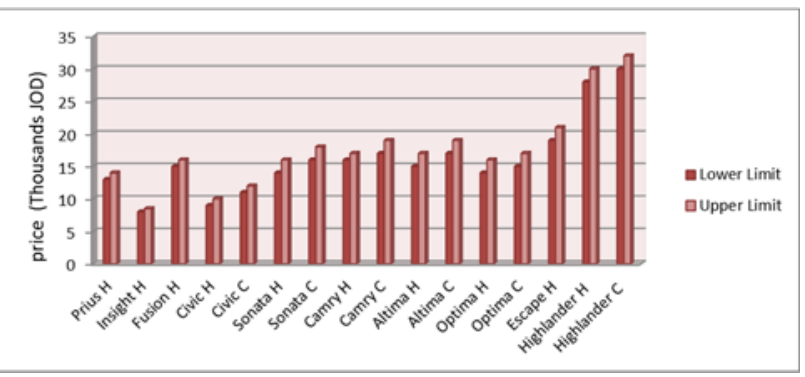

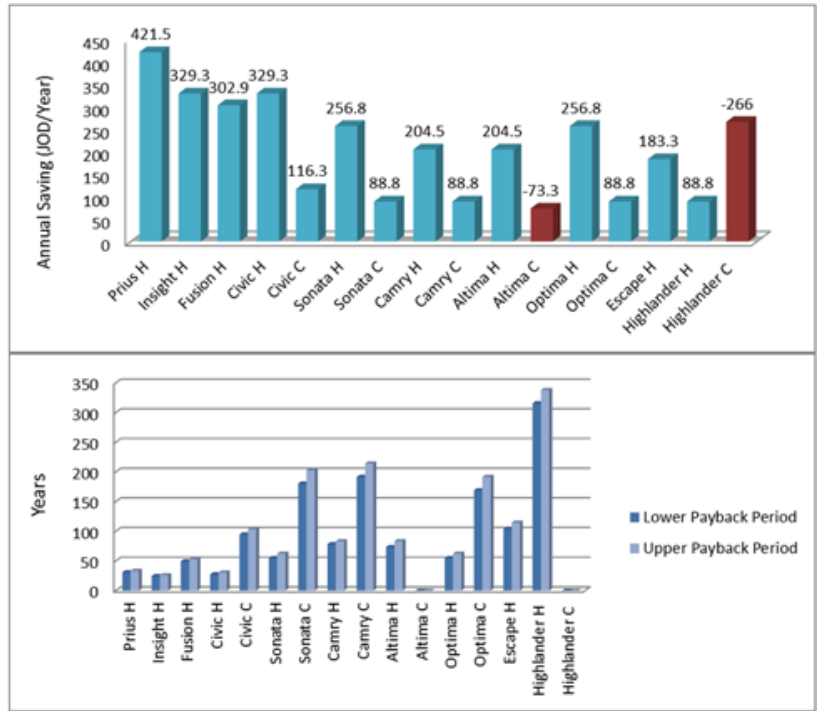

Figure 18: Economical characteristics for 2011 models

2012: Payback periods for HEVs are lower than payback periods for conventional models, increasing the MPG of Toyota Camry, improved its payback period even if that the initial price has increased (60.7-63.8 years instead of 78.2-83.1 years for 2011 model). (Figure 19)
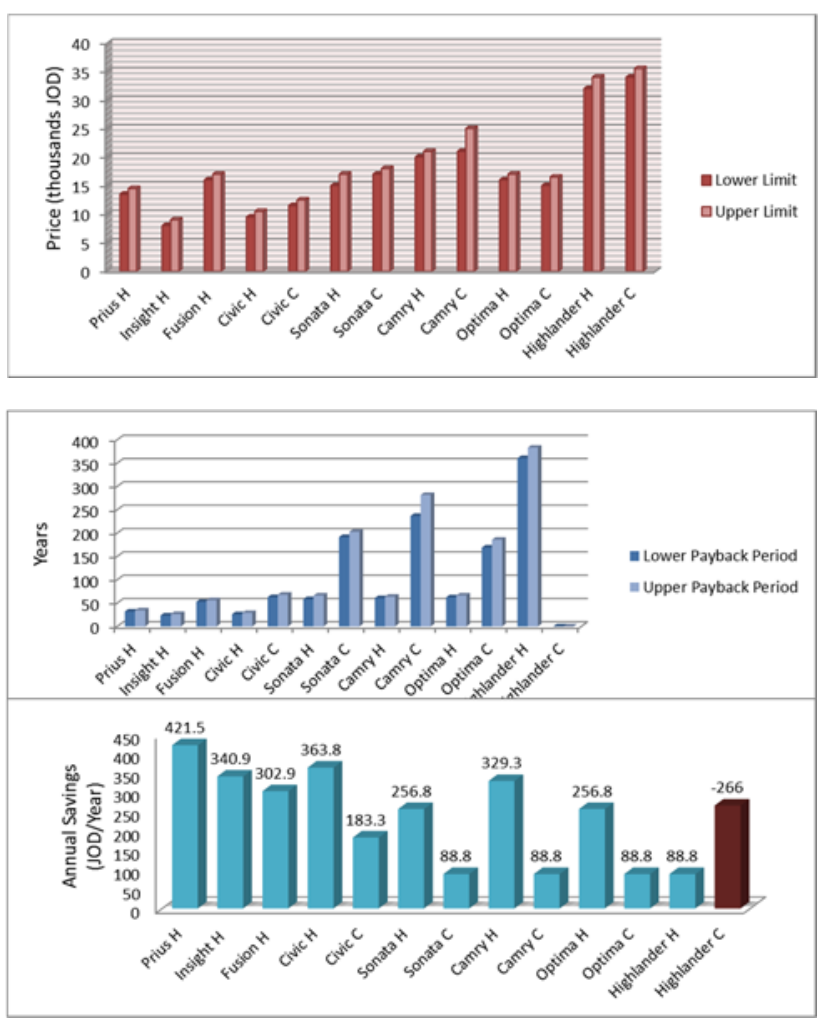

Figure 19: Economical characteristics for 2012 models

2013: Figure 20 shows the economical characteristics for 2013 models. 


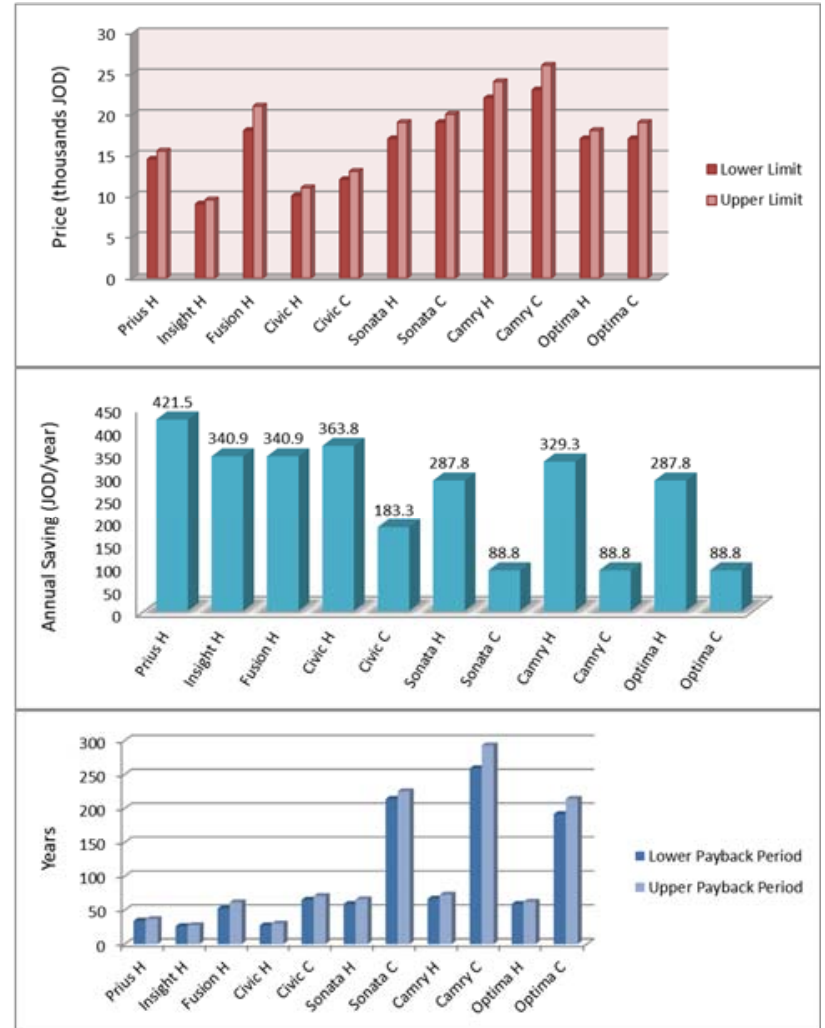

Figure 20: Economical characteristics for 2013 models

2014: The lowest price is for the Honda Insight (around 8 to 10 thousands JODs from 2011 to 2014), thus the payback period is the lowest (around 23 years in 2011 to 35 years in 2014). (Figure 21)
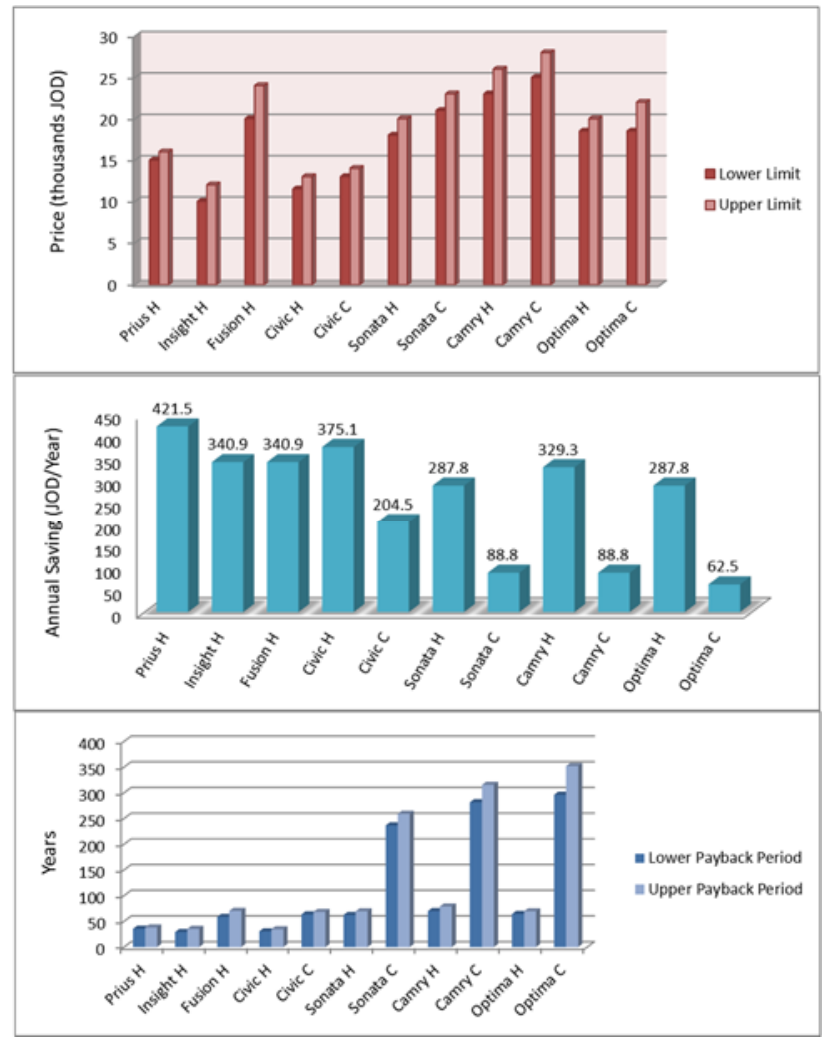

Figure 21: Economical characteristics for 2014 models
2015: The prices for 2015 models are fixed, thus having only one payback period. The best is for Toyota Prius (61.7 years), while the LS 600 has a MPG lower than the avg. MPG, thus has no payback period. (Figure 22)

A must mention information related to HEVs prices, is that the value of costumes in the local market on HEVs is $25 \%$ of its MSRPs, while the percentage is $64 \%$ for conventional cars.

So, MSRPs are higher for HEVs compared to their conventional counterparts, due to the extra cost associated with the additional electrical system (Batteries, Inverters, Motor/Generator units, Power cable, etc.). However, costumes cut off on HEVs, in the local market, leads to make HEVs cheaper than their conventional counterparts do.

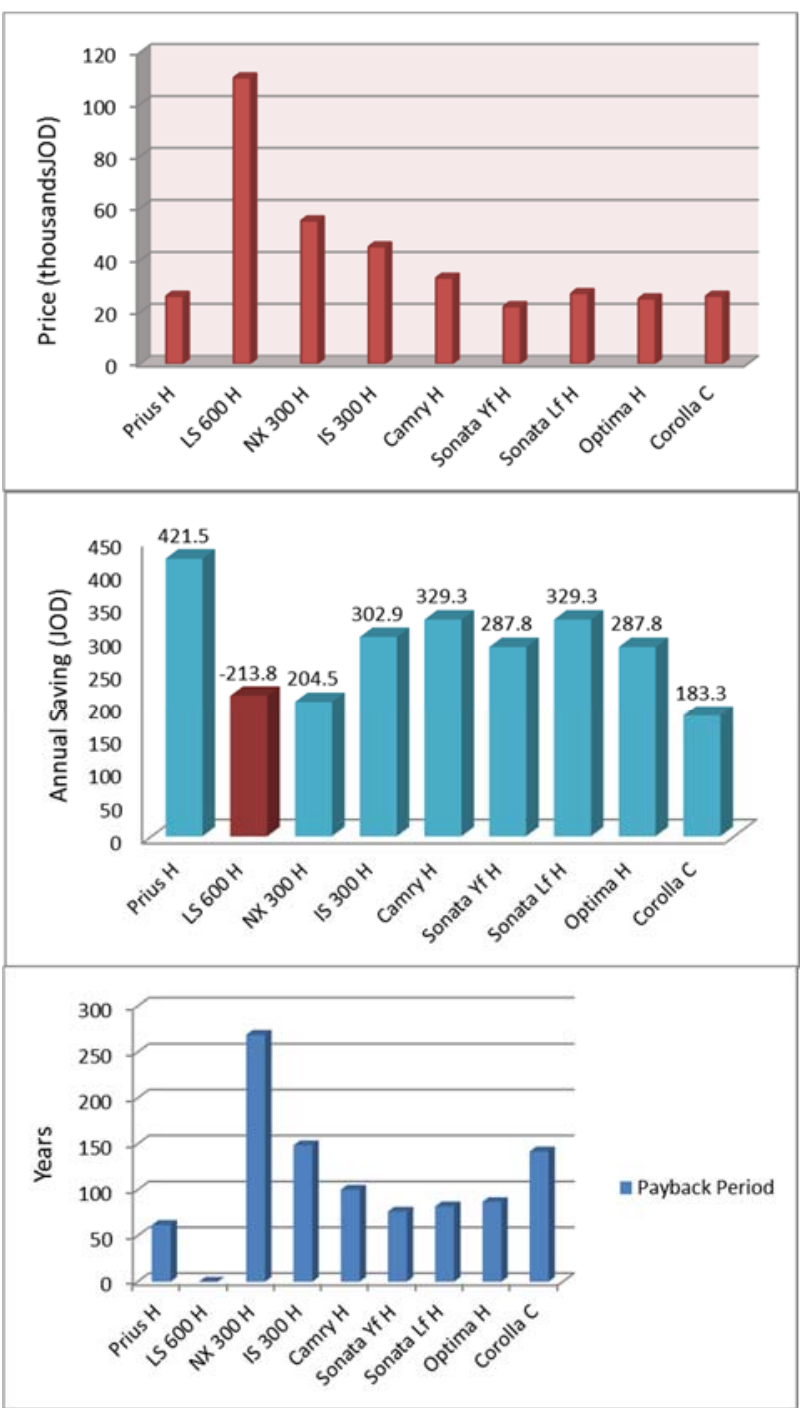

Figure 22: Economical characteristics for 2015 models

\section{- Battery Cost}

The type of the battery used for all the HEVs, is NI-MH except that for the Sonata hybrid, and the Kia Optima, which use Lipolymer batteries. 
The prices of the HEVs batteries according to the local market; are listed in Table 2 [25]. These values are not from the authorized manufacturers' maintenance center.

Table 2: Battery cost for various hybrid cars from the local market for models (2011-2014)

\begin{tabular}{|c|c|}
\hline $\begin{array}{c}\text { Car type } \\
(2011-2014)\end{array}$ & $\begin{array}{c}\text { Battery cost } \\
\text { (Best price in JOD) }\end{array}$ \\
\hline Prius & 1700 \\
\hline Insight & 1200 \\
\hline Fusion & 500 \\
\hline Civic & 1600 \\
\hline Sonata & 1900 \\
\hline Camry & 2200 \\
\hline Altima & 2400 \\
\hline Optima & 2000 \\
\hline Escape & 500 \\
\hline Highlander & 3000 \\
\hline
\end{tabular}

As shown in Table 2 for cars' models (2011-2014), the Toyota Highlander battery costs the highest (3000 JOD) among other types, whereas Ford Fusion and Ford Escape batteries are the cheapest (500 JOD).

The values of the $2015 \& 2016$ batteries from the authorized maintenance center are listed in the Table 3 . However, battery prices have not changed for most of the HEVs.

Table 3: Battery replacement costs for various hybrid cars from authorized maintenance centers (2015)

\begin{tabular}{|c|c|}
\hline $\begin{array}{c}\text { Car type } \\
(2015)\end{array}$ & $\begin{array}{c}\text { Battery cost (best price in } \\
\text { JOD) }\end{array}$ \\
\hline Prius & 2000 \\
\hline LS 600 & 3200 \\
\hline NX 300 & 3200 \\
\hline IS 300 & 3200 \\
\hline Camry & 2600 \\
\hline Sonata Yf & 9050 \\
\hline Sonata Lf & 9050 \\
\hline Optima & 9050 \\
\hline
\end{tabular}

The prices from the authorized maintenance centers are slightly higher (except that for Li-Poly batteries) than the prices found in the local market. Both Hyundai Sonata and Kia Optima use the same battery (lithium polymer) that's why they have the same replacement cost.

\section{Survey}

In order to get closer to the drivers' point of view about HEVs, a survey was carried out on a small number of drivers (36 university students), fifteen of them were driving HEVs, while the rest drive conventional cars as listed in Table 4.

Table 4: Drivers involved in the survey

\begin{tabular}{|c|c|c|}
\hline $\begin{array}{c}\text { Number of } \\
\text { students }\end{array}$ & HEVs' Owners & $\begin{array}{c}\text { Conventional Cars' } \\
\text { Owners }\end{array}$ \\
\hline 36 & 15 & 21 \\
\hline
\end{tabular}

The survey intended to figure out the pros and cons of HEVs, from owners' point of view, and the difference in maintenance behavior between the two groups. Also the second group (conventional cars owners) were asked if they would like to switch to a HEV.
The results of the survey were plotted separately for each question.

\subsection{HEVs Group}

When the drivers were asked where they do the maintenance of their cars, the results show that 7 out of 15 of them go to the manufacturers' maintenance centers, see Figure 23.

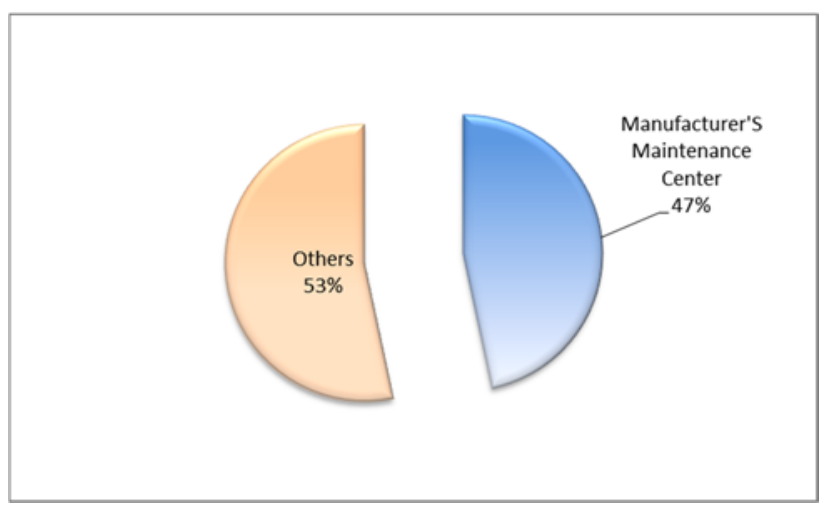

Figure 23: Maintenance behavior of HEVs owners

The second question were to know what are the favorable specifications (specs) in HEVs, Figure 24 shows that the most favorable spec is its fuel economy (High MPG).

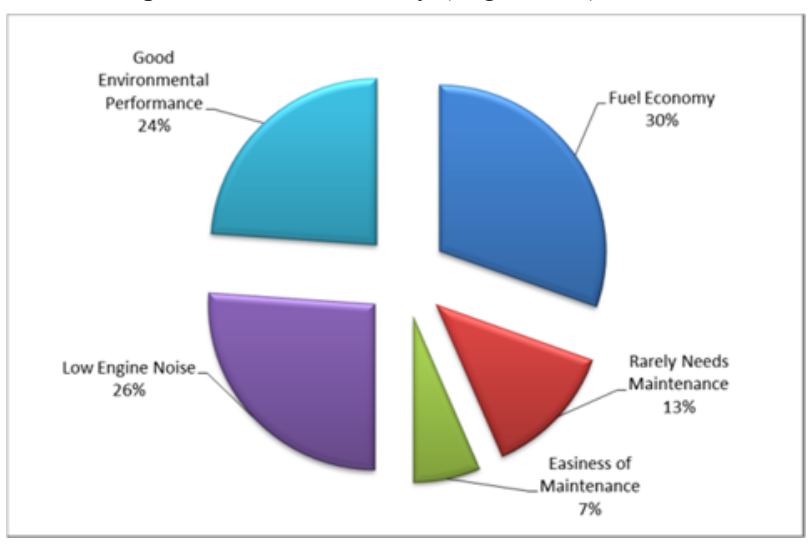

Figure 24: Most favorable specs of HEVs

The non-favorable specs are shown in Figure 25.

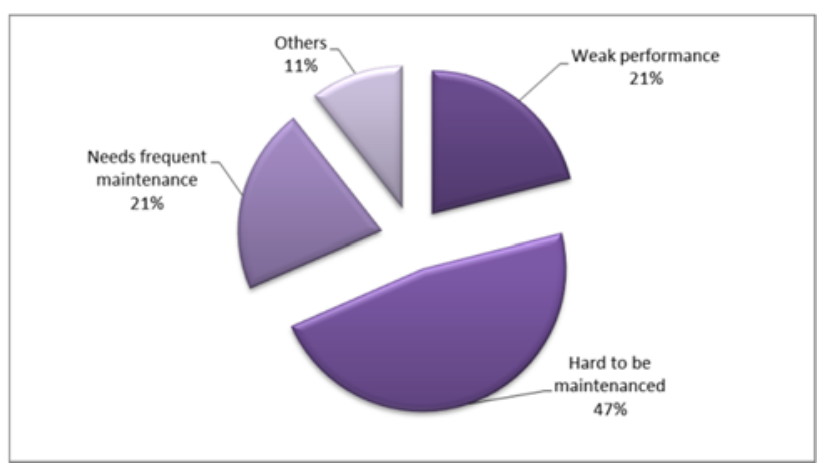

\section{Figure 25*: Non-favorable specs of HEVs}

*Note that these percentages indicate the repetition of the favorable, non-favorable specs among total number of checks, not among total number of students. 


\subsection{Conventional Cars Group}

When the drivers were asked where they do the maintenance of their cars, Figure 26 shows the results, only 6 out of 21 of them go to the manufacturers' maintenance centers.

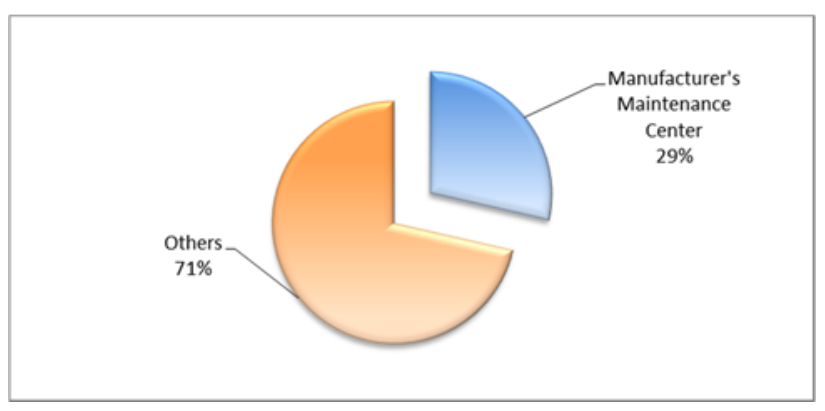

Figure 26: Maintenance behavior of conventional cars' owners

This shows that HEVs' owners prefer the manufacturers' maintenance centers more that the owners of conventional cars.

The percentage of the conventional cars' owners who would switch to a HEV is $51 \%$ (11 out of 21 drivers), see Figure 27.

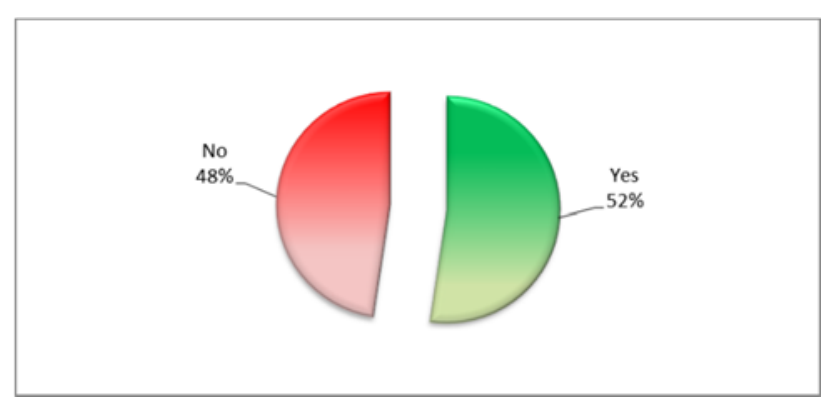

Figure 27: Number of conventional cars' owners who would switch to a HEVs

\section{Conclusion}

HEVs are essentially conventional cars, which are equipped with an external electrical system to supplement the work of the ICE. HEV may be categorized according to their types and levels. The types are: series, parallel and series-parallel. The series is the lightest but least efficient, the parallel system is more efficient (appears in Hyundai, and Honda HEVs) and the series-parallel is the most efficient (appears in all Toyota, Lexus, and Nissan HEVs). Where the levels are: micro, mild and full. Micro hybrid car is a conventional car, which is equipped only with a small electrical system to allow the startstop technique. Mild is a little bit larger and is capable of doing both the regenerative braking and the start-stop techniques, full hybrid are the most common presently and besides what mild hybrids can do, it can ensure the EV mode where the motor only propels the wheels.

HEVs have two special features that make them very fuel efficient as compared to the conventional cars; the regenerative breaking, and the start-stop technology. The performance characteristics of HEVs compared to the conventional counterparts are slightly better, when the engine size is the same; this is because of the presence of the extra electrical system in the HEVs. The HEVs also can be found in a variety of types (SUVs, sedan, AWD, FWD, hatchback, etc.) that fits all drivers' preferences. The $\mathrm{CO}_{2}$ emissions of HEVs are lower than the conventional for all of the car models.

Honda hybrid cars (Civic and Insight) have the smallest engines size among the rest of the hybrid cars $(1.3 \mathrm{~L})$, making them the least preferable cars when only concerning cars' performance. Toyota Prius has the best environmental performance (it only emits $178 \mathrm{~g} / \mathrm{mile}$ ). However, it has a larger ICE size than the Civic hybrid and Insight hybrid, Prius is capable of reducing the $\mathrm{CO}_{2}$ emissions due to its sophisticated control system, which also permits the highest MPG over the rest of the competitive hybrid cars.

Honda Insight has the best economical characteristics, so it is the most preferable when considering economical characteristics. However, Toyota Prius has the best MPG, and environmental characteristics, while having a moderate output power, and very good economical characteristics.

A survey was conducted among students in Jordan showing that the most favorable specifications of the HEVs are their fuel economy and friendly environment.

$\mathrm{HEVs}$ reduce $\mathrm{CO}_{2}$ emission and fuel consumption as compared to the conventional cars.

\section{References}

[1] Honda Worldwide," IMA", November 14, 2015, from www.world.honda.com/automobile-technology/IMA/

[2] Carsdirect, 2013," A Brief History of Hybrid Cars", November 28, 2015, from

http://www.carsdirect.com/green-cars/a-brief-history-ofhybrid-cars

[3] Eng. Ahmad Aqel, "What is a Hybrid vehicle", Toyota Hybrid training, Amman-Jordan.

[4] Eng. Disaku Morinaga, "Hybrid Cars guideline", Tokyo, Japan.

[5] Ruprekha Brahmachari, 2010, "Hybrid cars", Indo German Winter Academy.

[6] Iqbal Husain, 2005, ELECTRIC and HYBRID VEHICLES Design Fundamentals, CRC PRESS, Boca Raton London New York Washington, D.C. Chap. 10.

[7] Macomb Community College, Centre for Advanced Automotive Technology CAAT, "HEV levels", December 1, 2015, from www.autocaat.org/Technologies/Hybrid_and_Battery_ Electric_Vehicles/HEV_Levels

[8] Raf Catthoor, and Freek Beeckman, "CarEcology: New Technological and Ecological Standards in Automotive Engineering", Module 3. Department IWT, Karel de Grote-Hogeschool, Antwerp - Belgium.

[9] Ehsani Mehrdad, Gao Yimin, E. Gay Sebastien, and Emadi Ali, Modern Electric, Hybrid Electric, and Fuel Cell Vehicles Fundamentals, Theory, and Design, CRC PRESS, Boca Raton London New York Washington, D.C. 
[10] Astro camp school, 2015, "The Greenhouse effect", December 4, 2015, from www.astrocampschool.org/greenhouse-effect/

[11] U.S Environmental Protection Agency, EPA, "Climate change", December 4, 2015, from

www.EPA.gov/climatechange

[12] Prof. Z. S. Spakovszky, 2006, "The Internal combustion engine (Otto Cycle), Thermodynamics and Propulsion", Massachusetts Institute of Technology MIT, UK.

[13] Gunston, Bill, 1999, Development of Piston Aero Engines 2 ed. Patrick Stephens Ltd., Sparkford, UK.

[14] Tony Martin, 2010, "Old Engine Designs are New Again”, December 5, 2015, from www.searchautoparts.com/motorage/training/oldengine-designs-are-new-again

[15] Toyota Co., "Toyota Hybrid system: The Engine", course 071 , section 4 .

[16] Jack Erjavec, 2010, AUTOMOTIVE TECHNOLOGY A SYSTEMS APPROACH 5th edition, Delmar, Cengage Learning, Clifton Park, NY.
[17] Battery University, "Are Hybrid Cars Here to Stay?" December 7, 2015, from www.batteryuniversity.com/learn/article/are_hybrid_ca rs_here_to_stay

[18] Toyota Co., "Toyota Hybrid system: Hybrid System Overview", course 071, section 1.

[19] Eng. Ahmad Aqel, “THS II”, Toyota Hybrid training, Amman-Jordan.

[20] Eng. Ahmad Aqel, "THS System Operation", Toyota Hybrid training, Amman-Jordan.

[21] Hyundai Motor Company, 2015, "Sonata LF HEV Tech Highlight", Service Tech Academy.

[22] Hyundai Worldwide, "Sonata Hybrid", November 21, 2015, from www.worldwide.hyundai.com/WW/ Showroom/Eco/Sonata-Hybrid/PIP/index.html

[23] Edmunds Inc., December 16, 2015, from www.Edmunds.com

[24] U.S Environmental Protection Agency, EPA, December 16, 2015, from www.fueleconomy.com

[25] Jordan Local Market Shops, 2016. 